\title{
An atypical variational canal in the hip bone
}

\author{
Nihal Apaydın ${ }^{1}$, Emine Kızlkanat ${ }^{2}$, Neslihan Boyan ${ }^{2}$, Ayla Sevim ${ }^{3}$, İbrahim Tekdemir ${ }^{1}$ \\ ${ }^{1}$ Department of Anatomy, Ankara University School of Medicine, Ankara, Turkey \\ ${ }^{2}$ Department of Anatomy, Faculty of Medicine, Cukurova University, Adana, Turkey \\ ${ }^{3}$ Department of Paleoanthropolgy, Faculty of Letters, Ankara University, Ankara, Turkey
}

\begin{abstract}
We report, to our knowledge, a previously unreported canal on the hip bone belonging to the left side of an adult male skeleton. Anterior aperture of the canal was located just anterior to the auricular surface and the posterior aperture just above the major sciatic notch. The margin of the anterior aperture which is located on the left iliac fossa was regular and in the form of a complete circle. The posterior aperture was possessing more than one foramen which are divided by bony segments. We failed to find the other pair of the hip bone, so we could not determine whether the right hip bone possesses a similar canal or not. In this case report we aimed to evaluate this canal morphometrically and point out its clinical importance.
\end{abstract}

Key words: the hip bone; variation; pelvis fixation

Anatomy 2008; 2: 60-62, (c) 2008 TSACA

\section{Introduction}

The hip bone is one of the major bones which constitute the pelvis. Besides its structural importance, it is one of the main bones operated on during hip arthroplasty and iliosacral screw insertion. ${ }^{1,3}$ Superior gluteal artery and nerve injuries are common complications during these operations. ${ }^{4-7}$ Current literature contains satisfactory studies regarding the variations in the course of these neurovascular structures and their relation to the hip bone. But less attention paid on the hip bone which can also possess structural variations. We now report, to our knowledge, a previously unreported canal on the hip bone belonging to the left side of an adult male skeleton which took our attention during a routine laboratory session with medical students. At first glance, it was doubtful to decide that whether this variational canal is traumatically or structurally formed. So, we decided to examine this canal radiologically and by this occasion we aimed to evaluate this previously unreported canal morphometrically and point out its clinical importance.

\section{Case Report}

During our routine skeletal system observations we have noticed a canal on the hip bone belonging to the left side of an adult male skeleton (Figure 1). The anterior aperture of this canal which is located on the left iliac fossa just above the auricular surface had a regular margin in the form of a complete circle (Figure 2). The antero-posterior diameter of this canal was measured as $9.8 \mathrm{~mm}$ and the supero-inferior as $10.2 \mathrm{~mm}$. The closest mean distances of this aperture between the iliac crest, anterior superior iliac spine (ASIS) and the anterior inferior iliac spine (AIIS) was measured as 73.8, 86.6, 70.2 $\mathrm{mm}$ respectively. The closest distance between the greater sciatic notch and this canal was 17.2 and it was as close as $5.6 \mathrm{~mm}$ to the auricular surface.

The posterior aperture of this canal is located on the gluteal surface just above the greater sciatic notch. And it is possessing more than one foramen which are divided by bony segments. The closest distance between this 


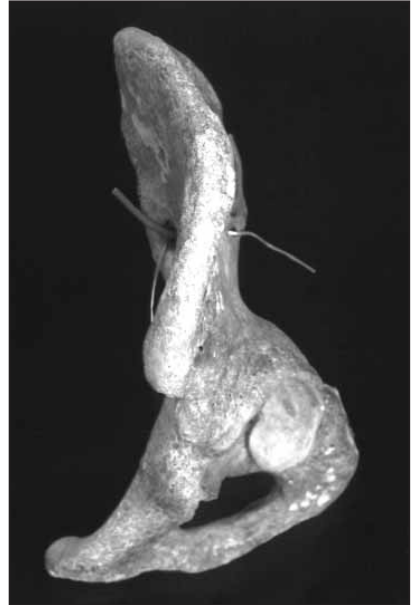

Figure 1. Lateral view of the left hip bone of an adult male skeleton showing the variational canal.

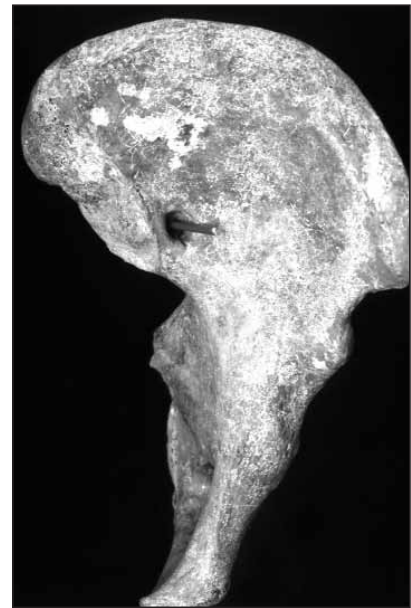

Figure 2. Medial view of the left hip bone showing the anterior aperture of the variational canal. partite aperture and ASIS, AIIS, posterior superior iliac spine (PSIS), posterior inferior iliac spine (PIIS) was measured as 103.6, 83.9, 47.5, $23.7 \mathrm{~mm}$ respectively. The aperture of this canal is composed of three different foramens separated from each other by three bony lamellas (Figure 3). The largest of these foramens is located posteriorly and its long axis is directed antero-posterior direction. The diameter measured from this axis was 8.1 $\mathrm{mm}$, and from the supero-inferior axis was $4.5 \mathrm{~mm}$. The second of these foramens is located anterior and superior to the former one. Its antero-posterior diameter was measured as $2.8 \mathrm{~mm}$, and supero-inferior diameter as 5.1 $\mathrm{mm}$. The third foramen is located anterior to the first and inferior to the second foramen. Its antero-posterior diameter was measured as $5.6 \mathrm{~mm}$, and supero-inferior diameter as $3.5 \mathrm{~mm}$.

The whole length of the variational canal was measured as $33.9 \mathrm{~mm}$.

The radiological image of the hip bone revealed neither signs of fracture healing such as granulation tissue or callus formation nor a sign of an operation or a foreign body such as drop shut or screw (Figure 4).

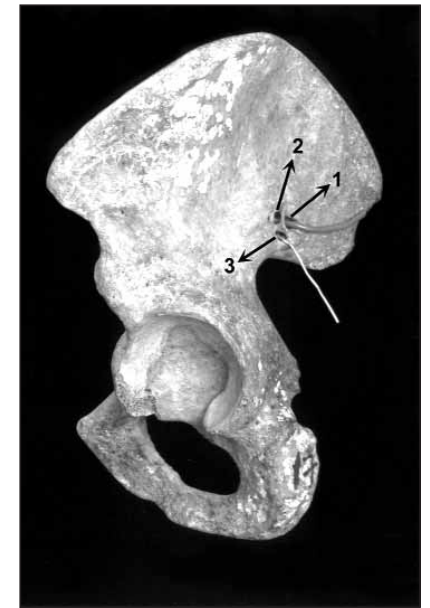

Figure 3. Postero-lateral view of the left hip bone showing the posterior aperture of the variational canal. 1, 2 and 3 are enumerated to show the three different foramens separated from each other by three bony lamellas.

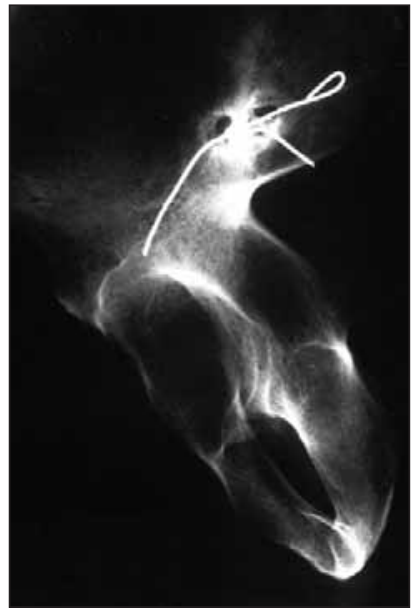

Figure 4. The radiological image of the hip bone showing the variational canal.

\section{Discussion}

The hip bone is a bone that can show some structural differences among male and female gender. But according to our knowledge the anatomical variations related to the hip bone is not a common finding. There is evidence that certain trait categories are mediated through sexual dimorphism. It has been suggested that males and females respond differently to alterations in skeletal growth such that trait presence may be associated with sexual characteristics. ${ }^{8}$ In 1978, Finnegan have reported a number of non-metric variations seen in various bones of the infracranial skeleton. In this series, the traits were categorized according to sex, racial group and side-to-side differences. He noticed that certain traits are seen more in male gender and on left side when compared with females and right sides. ${ }^{9}$ The variation reported in our case has no relation with sexual dimorphism but since the hip bone we report is belonging to the left side of male skeleton, this variation make us think that it can be structural.

According to our knowledge, this variational canal that is presented in this case report has not been defined previously. It was doubtful to decide whether this varia- 
tion is traumatic or structural at first glance. But since the radiography showed no signs of fracture healing such as granulation tissue or callus formation, we suggest that this canal is a structural anatomical variation.

It is doubtful whether this canal contain any neurovascular structures or not but it has still importance in surgical aspect. For example, during the operations directed to displaced and unstable pelvic fractures, one approach is separation of sacroiliac joint anteriorly and placements of two-hole double plate. During this procedure when the inferior plate is placed above the safe zone, the plate located on the ilium can enter through the defined variational canal. As a result, the plate would be unstable. The same situation is also valid during placement of the inferior bar in iliosacral bar operations in fixation of unstable pelvic fractures when approached posteriorly. ${ }^{10}$ Goryzca et al. have compared the strength of iliosacral lag screws and transiliac bars and reported that the transiliac bars are stronger than iliosacral fixation. ${ }^{3}$ Iliosacral screwing is a popular technique for reducing the complicated fracture of pelvis. In these operations, the insertion site for iliosacral screws lies along the posterior ilium between greater sciatic notch and the iliac crest. ${ }^{11}$ But in the presence of such a canal, it is obvious that the fixation would be unstable without considering the type of approach applied. Thus any fixation method would not be strong enough to allow full weight-bearing of the patient.

As a result, the hip bone can bear different structures rather than its well-known anatomy. This condition must be paid attention when evaluating the patient radiologically or during planning surgery. It must be kept in mind that the hip bone can posses such a variational canal and it may contain neurovascular structures those can be important during operations directed to pelvis.

\section{References}

1. Collinge C, Coons D, Aschenbrenner J. Standard multiplanar fluoroscopy versus a fluoroscopically based navigation system for the percutaneous insertion of iliosacral screws: a cadaver model. 7 Orthop Trauma 2005; 19: 96-101

2. Gorczyca JT, Varga E, Woodside T, Hearn T, Powell J, Tile M. The strength of iliosacral lag screws and transiliac bars in the fixation of vertically unstable pelvic injuries with sacral fractures. Injury 1996; 27: 561-4.

3. Ikeuchi M, Kawakami T, Yamanaka N, Okanoue Y, Tani T. Safe zone for the superior gluteal nerve in the transgluteal approach to the dysplastic hip: intraoperative evaluation using a nerve stimulator. Acta Orthop 2006; 77: 603-6.

4. Farrell CM, Springer BD, Haidukewych GJ, Morrey BF. Motor nerve palsy following primary total hip arthroplasty. 7 Bone foint Surg Am 2005; 12: 2619-25.

5. Perez MM, Llusa M, Ortiz JC, et al. Superior gluteal nerve: safe area in hip surgery. Surg Radiol Anat 2004; 26: 225-9.

6. Finnegan M. Non-metric variation of the infracranial skeleton. 7 Anat 1978; 125: 23-37.

7. Matta JM, Saucedo T. Internal fixation of pelvic ring fracture. Clin Orthop Relat Res 1989; 242: 83-97.

8. Moed BR, Karges DE. Techniques for reduction and fixation of pelvic ring disruptions through the posterior approach. Clin Orthop Relat Res 1996; 329: 102-14.

9. Eksioglu F, Uslu M, Gudemez E, Atik OS, Tekdemir I. Reliability of the safe area for the superior gluteal nevre. Clin Orthop Relat Res 2003; 412: 111-6.

10. Picado CH, Garcia FL, Marques W J. Damage to the superior gluteal nerve after direct lateral approach to hip. Clin Orthop Relat Res 2007; 455: 209-11.

11. Saunders SR. Nonmetric skeletal variation. In: Iscan MY, Kennedy KAR, eds. Reconstruction of Life from the Skeleton. New York: Alan R. Liss, Inc; 1989. p. 95-108.

\footnotetext{
Correspondence to: Nihal Apaydın, MD

Department of Anatomy,

Ankara University Medical School

Sihhiye 06100 Ankara, Turkey

Phone: +90 31231050 01; Fax: +90 3123105001

e-mail: nihalapaydin03@yahoo.com

Conflict of interest statement: No conflicts declared.
} 